\title{
Constraining the intermediate sulfur species involved in sedimentary pyrite formation
}

\author{
RAISA ISLAM AND ELIZABETH D. SWANNER ${ }^{1}$ \\ ${ }^{1}$ Iowa State University, Department of Geological \& \\ Atmospheric Sciences, Ames, IA 50010 USA, \\ eswanner@iastate.edu
}

Sedimentary pyrite is one of the most abundant minerals on the Earth's surface, and plays a major role in the sulfur cycle by being the sink for up to $35 \%$ of marine sulfur. The abundance of sedimentary pyrite in organic-rich shales affects the quality of the petroleum extracted by "souring" the oil (through pyrite oxidation and subsequent $\mathrm{H}_{2} \mathrm{~S}$ production). Despite the relevance of sedimentary pyrite in element cycling as well as the quality of petroleum reserves, the chemical pathways that lead to its formation are poorly constrained, and often debated. In low temperatures, pyrite $\left(\mathrm{FeS}_{2}\right)$ formation starts by microbial sulfate reduction to form sulfide $\left(\mathrm{S}^{2-}\right)$, which is then oxidized to the average state $\mathrm{S} 1$ that we find in pyrite. The mechanisms that lead to this oxidation are unclear, with little knowledge about what intermediates are involved in the pyrite formation. Lab-based experiments show that pyrite forms when $\mathrm{FeS}$ reacts with elemental sulfur $\left(\mathrm{S}^{0}\right)$ or polysulfides $\left(\mathrm{S}^{1-}\right.$ and $\left.\mathrm{S}^{0}\right)$, or via the sulfidation of $\mathrm{Fe}$ (III) (oxyhydr)oxides. However, these pathways require validation in anoxic sediments. One barrier to this has been the difficulty in detecting and quantifying aqueous and solid phase sulfur intermediates.

To investigate the potential mechanisms of sedimentary pyrite formation, we collected (pore)waters, authigenic (water-column particulates) and diagenetic sediments from Brownie Lake in Minneapolis, MN. Brownie Lake is a meromictic lake with ferruginous (anoxic and iron-rich) bottom waters where dissolved iron concentrations exceed $>1000 \mu \mathrm{M}$ and where maximum sulfate concentrations are 80-100 $\mu \mathrm{M}$. We used bulk and microscale techniques to detect sulfur species in our samples. Mössbauer spectroscopy of the water-column particulates shows a very reactive $\mathrm{FeS}$ phase, while voltammetry documented electroactive FeS colloids. Bulk X-Ray fluorescence (XRF) of the lake sediments shows $0.5 \mathrm{wt} \% \mathrm{~S}$ and $7 \mathrm{wt} \% \mathrm{Fe}$. Synchrotronbased X-Ray Absorption Spectroscopy (XAS) indicates pyrite is forming progressively downcore, and documents the presence of $\mathrm{S}$ intermediates such as sulfite and thiosulfate, which could be involved in the formation of pyrite. 